\title{
The positive in the tragic: Covid pandemic as an impetus for change in teaching and assessment in higher education
}

\author{
Ottavia Trevisan ${ }^{\mathrm{a}}$, Marina De Rossi ${ }^{\mathrm{b}}$, Valentina Grion ${ }^{\mathrm{c}}$ \\ ${ }^{a}$ University of Padova, Italy, ottavia.trevisan@unipd.it, https://orcid.org/0000-0003-0522-935X \\ ${ }^{b}$ University of Padova, Italy, marina.derossi@unipd.it, https://orcid.org/0000-0002-5115-8196 \\ ${ }^{c}$ University of Padova, Italy, valentina.grion@unipd.it, https://orcid.org/0000-0002-2051-1313
}

\begin{abstract}
The spread of Covid-19 pandemic upturned higher education routines, inducing a shift to online learning which sometimes translated into a huge leap towards didactic experimentation. While exposing critical issues in existing teaching methodologies and assessment processes, such emergency distance education condition could spark meaningful educational innovation. This paper describes an international study engaging teachers of professionalizing courses in the educational area across the world $(N=120)$. The aim was to investigate their perception of the induced distance education in terms of teaching methodology and assessment practices. Emerging findings indicate a silver lining in the midst of the pandemic storm, as teaching practices gear more towards being student-centred.
\end{abstract}

Keywords: higher education faculty; ICT integration in higher education; distance education.

\section{Introduction}

The emergency resulting from the spread of the COVID 19 pandemic involved many countries and different educational contexts in the search for appropriate solutions and strategies (UNESCO, 2020). Higher Education often completely reorganized their teaching methods and didactic functions, getting in a position to use flexible and differentiated forms of E-Learning using technological resources, with the aim to guarantee the right to education of their students (Crawford et al., 2020).

One of the greatest challenges for the higher education teachers, for example in the Italian context, was to overcome the misconception that e-learning is simply a substitute for traditional classroom teaching in presence, where it is sufficient to transfer one's usual teaching online (Corsi et al., 2019).

This widespread unawareness risks to confuse Emergency Remote Teaching and Online Learning (Hodges et al., 2020). Over the past two decades, studies in the field of educational technology carefully defined the design of different educational models; multiple solutions and methodologies have been implemented and studied including various types of blended learning formats, distributed and collaborative distance learning environments, mobile learning, and online learning (Garrison \& Vaughan, 2008; Moor et al, 2011; Major, 2015). An element emerging from this research is that learning through hybrid solutions or completely at a distance is effective only when aligned to a careful instructional design that is able to implement systematic methodological and evaluative models contextualized in specific learning environments (Gabel et al. 2014; De Rossi, 2019).

Research on content-student, teacher-student, and student-student interaction is one of the most robust areas of distance learning research (e.g. Moore \& Diehl, 2018), and shows how each of these interactions may increase learning outcomes as socio-cognitive processes, when integrated in a meaningful way (Robert et al., 2009).

In Online Learning, Blended Learning and other hybrid solutions with ICT, instructional formats, and types of interaction affect the quality of instruction and require time-tested use, choice of resources, and infrastructure that cannot be improvised. The need is to spread digital literacy in education, not only among experienced researchers in the field but among educators and faculty in schools and universities to foster high-quality, inclusive and accessible digital education (European Commission, 2020). 


\section{The positive in the tragic. Covid Pandemic as an impetus for change in teaching and assessment in HE}

\section{O. Trevisan, M. De Rossi, V. Grion}

A careful design process has failed to characterize most instances of the pandemic emergency education, and this may carry the risk of stigmatizing distance learning when compared to face-to-face learning, failing to consider that the transition to distance education has often not allowed for the full potential of online formats to be displayed (Hodges et al., 2020).

Said methodological aspect recalls once again what has been debated for decades about the profile of pedagogical and didactic competence of higher education teachers, particularly in professionalizing courses such as those for teacher and educator training (Perry et al., 2019). These are meant to develop diversified and flexible teaching skills, related to the ability to understand and facilitate students' learning processes (Tigelaar et al., 2004), also with integrated and varied use of ICT (Brown, 2015; De Rossi \& Ferranti, 2017).

According to authoritative international sources, these skills should be acquired progressively with experience, with the support of the academic institution and continuing education (High-Level Group on the Modernisation of Higher Education, 2013). Among the paths set out for the qualification of the university teacher's skills, specific focus is given to courses aimed at the development of methodological and didactic capabilities, considered an essential condition to raise the overall quality of student results (Gaebel \& Zhang, 2018).

However, some recent studies on the effects of the pandemic in the academic field showed that, from this point of view, methodological innovation integrated with technological innovation is not yet a consolidated practice (e.g., Hodges et al., 2020; Lowenthal et al., 2020). In the current situation of emergency distance learning, in many cases the strategies adopted mainly aimed at providing access to education, rather than redefining the educational framework (Hodges et al., 2020; Lowenthal et al., 2020; Trevisan et al., 2020). Incident factors are multiple, also traceable in the general pre-COVID 19 conditions: the lack of resources and support structures for teachers by the universities; the lack of continuous training in design, methodology, and technology; the lack of awareness in the teaching staff of the necessary transition to studentcentred didactics aimed to foster the construction of skills, rather than only knowledge (Khaddage, Fayad, \& Moussallem, 2020; Safi, Wenzel, \& Spalding, 2020).

The pandemic, while highlighting many critical issues in higher education, also represents a global challenge, an opportunity to question and redefine the way higher education develops teaching solutions useful to support innovation, academic quality, and curriculum standards (Crawford et al., 2020). This is even more evident in relation to the assessment processes, too often still dominated by old-style traditional methods (Joughin, Dawson \& Boud, 2017; Grion \& Serbati, 2019). The current pandemic has undoubtedly exposed some of the frailties of existing assessment practices, which could in time become more authentic, fit-for-purpose, robust and resilient. At the same time, the immediate responses enacted also highlighted some extremely positive opportunities for those who seek to modernize assessment so as to promote student learning (De Rossi et al., 2020; Sambell \& Brown, 2020).

The article presents an international explorative study coordinated by the University of Padua (Italy) and the University of North Texas (USA), investigating how the trainers of professionalizing courses in the educational area (TPCE) perceive the current transition from face-to-face to online-based teaching. This study aimed to understand both whether the impact of forced distance education stimulated TPCE to develop active, collaborative and reflective student-centred approaches, and whether the changes have sparked intentions to maintain distance education strategies even when normal conditions may return. The hypothesis of the study is that the unavoidable change in teaching strategies (now with a crucial ICT component), could stimulate the faculty to innovate teaching practices from a design, methodological and evaluation point of view, with the right institutional support (Fedeli et al., 2020).

The research thus wants to understand how TPCE perceived the impact of forced distance education (DE) in their teaching and evaluation methodologies. Hopefully, the findings of this study will help in understanding how TPCE in higher education coped with the abrupt upturn of instruction caused by the pandemic. In turn, said understanding could be useful to scholars and policymakers when ideating future strategies to support at best the realization of effective and efficient distance teaching for learning, during crisis and not.

\section{Current study}

This international study engages higher education institutions worldwide $(\mathrm{N}=120)$, and specifically their faculty dealing with training professionals in the educational area (TPCE). The sampling process followed a snowball logic method, starting from the two leading universities situated in Italy and USA, in the attempt to include a variety of participants around the globe. Overall, responses were gathered from four continents: Europe (N=58), North America $(\mathrm{N}=44)$, Oceania $(\mathrm{N}=12)$ and Asia $(\mathrm{N}=5)$, allowing for an international investigation of the phenomenon at stake.

The demographics of the respondents revealed a majority of female participants (61\%), with a $39 \%$ of male presence. Regarding teaching seniority, a large group of experienced faculty appears to have responded to the survey: $33 \%$ of the participants had over 20 years of teaching experience, whereas only $16 \%$ were in their first 5 years in the profession. 


\section{Higher Education Technology Survey}

The Higher Education Technology Survey was the main instrument of investigation in the present study (Trevisan et al., 2020).

The demographic section contained 10 demographic items $1^{1}$, namely: gender; seniority; scientific area of teaching; geolocation; availability of an ICT support centre at the employing university; access to university-provided online platform for DE; habits to keep up with educational ICT; professional development training for DE; usual didactic routines pre-pandemic and DE practices pre-pandemic.

The following section comprised 15 Likert-type items rated on a 6-point scale ${ }^{2}$ explored TPCE's perception of DE from the point of view of (a) challenges and opportunities for teaching and learning; (b) institutional support; and (c) possible consequences of the current situation on future teaching routines. Each of these 15 items was followed by a question going deeper into the participants' responses, inquiring for more details. The participants were asked the said follow-up questions and to rank the first three reasons supporting their answer in the relevant Likert scale item.

Overall, the instrument proved to be reliable (Chronbach's alpha .89), and exploratory factor analyses indicated the presence of at least three stable constructs, namely DE Enthusiasm (alpha $=.89$ ) related to enjoyment in performing DE, perception of productivity and efficiency; DE Perceived Support (alpha $=.74$ ) from the employing institution; and DE Resolve (alpha $=.88)$ concerning the perceived relevance of these practices for the future ${ }^{3}$.

This paper will focus on the analysis of data emerging from the follow-up questions investigating pre-pandemic and in-pandemic teaching practices, as well as reported possible ways of enacting DE elements in the future. Particular focus will be given to the phenomenon of (distance) evaluation, as crucial process in monitoring and tailoring teaching practices to learning stances.

\section{Results}

In the paragraphs below, results emerging from the Higher Education Technology Survey are presented. First, participants' most frequently used didactic approaches, along with DE strategies implemented prior to the pandemic, are introduced. Then, we see how participants are coping with DE during the pandemic, when they are compelled to use it as a routine. Finally, the reported possibility to implement DE elements in a post-pandemic education, in light of the emergency education experienced (Hodges et al., 2020) in the last few months, is investigated.

As previously described, the survey engaged an international sample of respondents with different local rates, and results will be presented pooled.

\subsection{Teaching approaches and practices prior to the pandemic}

In order to better understand participants' practices prior to the pandemic, they were asked about (a) their habits to keep up with educational technologies; (b) any training for DE practices within the last 5 years; and (c) possible previous experiences in DE (see Table 1). ${ }^{4}$

Table 1. Participants' characteristics - background variables.

\begin{tabular}{|c|c|c|c|c|}
\hline \multicolumn{2}{|c|}{ Statistics } & $\begin{array}{l}\text { Habit to keep up } \\
\text { with ed. ICT }\end{array}$ & Recent training for $D E$ & $\begin{array}{l}\text { Previous experience } \\
\text { with } D E\end{array}$ \\
\hline \multicolumn{2}{|c|}{ Mean } & 2.97 & 2.14 & 2.45 \\
\hline \multicolumn{2}{|c|}{ Std. deviation } & .75 & .91 & .87 \\
\hline \multicolumn{2}{|c|}{ Mode } & 3 & 2 & 2 \\
\hline \multirow[t]{2}{*}{$N$} & Valid & 119 & 117 & 120 \\
\hline & Missing & 1 & 3 & 0 \\
\hline
\end{tabular}

\footnotetext{
${ }^{1}$ Items in this section were either binary (e.g. gender), open ended (e.g. geolocation) or in a 4-point Likert scale (e.g. in-service training frequency).

${ }^{2}$ Likert: 1 = completely disagree; 2 = very much disagree; $3=$ somewhat disagree; $4=$ somewhat agree; $5=$ very much agree; $6=$ completely agree.

${ }^{3}$ Further information about the properties of the instrument can be found in Trevisan et al., 2020.

${ }^{4}$ The relative questions were 4 -point scales, $1=$ never to $4=$ always.
} 


\section{O. Trevisan, M. De Rossi, V. Grion}

Most participants stated to frequently attempt to keep up with ICT in education (mean= 3 out of 4 on the scale), with only a $1 \%$ reporting they would completely disregard the matter. Almost half of the participants $(48 \%)$ indicated having sometimes attended formal training sessions in distance education (mean $=2$ ), although up to $23 \%$ stated never having completed any training whatsoever. Previous DE practices engaged occasionally to frequently most of the surveyed population (mean $=2.4$ ), while $12-13 \%$, respectively, always and never employed this type of instruction in their routines, until the advent of Covid-19 pandemic.

When asked to report the two most commonly used didactic formats prior to the pandemic, most of the participants stated to implement a combination of lectures and group work activities in attendance (64.2\%), followed by a $41.7 \%$ realizing some online activities to accompany their face-to-face lessons, and only a $6.7 \%$ indicating group work activities in attendance as one of their two most used instruction formats (see Table 2).

\begin{tabular}{ll}
\multicolumn{2}{c}{ Table 2. Preferred didactic formats pre-pandemic } \\
\hline Formats $^{\mathrm{a}}$ & Valid percentage \\
\hline Lecture and group work in attendance & 64.2 \\
Face-to-face lessons with some online activities & 41.7 \\
Face-to-face lessons with many online activities & 26.7 \\
Lectures & 12.5 \\
Group work in attendance & 6.7 \\
\hline a Participants could select up to two options.
\end{tabular}

${ }^{\text {a }}$ Participants could select up to two options.

Digitally integrated education was not something new to most of the TPCE involved, although up to $20 \%$ of them stated having engaged with its means and strategies never to only occasionally5 before the strike of the pandemic (answers $\leq 3$ out of 4 ).

The respondents who did engage with technology-integrated strategies even before they became the core to DE during the pandemic were asked to rank their top three uses (see Table 3). The 57.3\% of these used it mostly to share materials with their students (e.g. PDFs and articles), while a 15.6\% of the TPCE realized digitally based activities to have the students create digital artefacts. Moreover, technologies were used to enable students to attend lessons remotely in real time by $10.4 \%$ of the participants using ICTs on a frequent basis.

Table 3. Digitally based teaching activities pre-pandemic.

\begin{tabular}{|c|c|}
\hline Prevailing reasons to use distance education in usual practice ${ }^{a}$ & Valid percentage \\
\hline To share materials with students (e.g. slides in pdf). & 57.3 \\
\hline To have the students create products (e.g. digital artefacts). & 15.6 \\
\hline To enable students to follow lessons remotely in real time. & 10.4 \\
\hline To interact with students about the teaching program. & 5.2 \\
\hline To allow students to view video-recorded lectures. & 4.2 \\
\hline To encourage the students to communicate with each other. & 2.1 \\
\hline To have the students perform group study/reflection tasks. & 2.1 \\
\hline To evaluate students. & 2.1 \\
\hline To encourage students' self-evaluation. & 1.0 \\
\hline To implement peer-evaluation. & 0.0 \\
\hline
\end{tabular}

Among the possible uses of DE-related strategies prior to the pandemic (see Table 3), there was also the use of digitally based means to perform evaluation. Very few participants indicated such options as their preferred use of technologies in education, with a $2.1 \%$ using them to evaluate, and a $1 \%$ to promote self-evaluation, while none of the respondents ranked technology first or used to implement students' peer evaluation.

Nevertheless, participants could choose and rank up to three preferred uses for DE. While not often the respondents' first choice, to evaluate students through digital means was within the first three choices of $13.3 \%$ of them. To encourage students' self-evaluation was within the first three preferences of up to $8.3 \%$ of participants, while peer-evaluation was mentioned by a cumulative $5 \%$.

\footnotetext{
${ }^{5}$ Four-point Likert scale: $1=$ never; $2=$ occasionally; $3=$ frequently; $4=$ always.
} 


\section{The positive in the tragic. Covid Pandemic as an impetus for change in teaching and assessment in HE}

\section{O. Trevisan, M. De Rossi, V. Grion}

\subsection{Experiencing Distance Teaching during a pandemic}

Considering how TPCE had to familiarize with a sometimes completely new type of instruction, the survey inquired as to the ease to carry out DE6. With an overall mean of 3.9 out of 6 (std. 1.2), participants seemed to indicate mild agreement with a perception of ease, although for a $31.7 \%$ of them ease was not so pronounced (answers $\leq 3$ out of 6 ). The remaining $68.3 \%$ was asked to rank the first three reasons to their answer. Looking at these respondents' first choice (see Table 4), it seems that DE facilitates work-life balance (28.2\%), along with easing communication with the students $(20.5 \%)$ and allowing for the adaptation of already-made online resources to the specific course $(16.7 \%)$.

Table 4. Distance Education perception during the pandemic: ease.

\begin{tabular}{ll}
\hline Prevailing reasons to perceived ease in performing DE ${ }^{\text {a }}$ & Valid percentage \\
\hline It facilitates management of work-life balance. & 28.2 \\
It facilitates communication with students. & 20.5 \\
It makes it possible to adapt to my course resources already available on the web. & 16.7 \\
There are many resources available online. & 15.4 \\
It facilitates the monitoring of students' learning processes. & 15.4 \\
It makes it possible to use MOOCs in my teaching. & 3.9 \\
\hline
\end{tabular}

${ }^{a}$ Rank the first three most relevant reasons. Here displayed the percentages for options ranked first.

Participants were also asked if 'using distance education improves [their] teaching' (6-point Likert scale). The item's mean was $4.0($ std.=1.3) indicating a fair agreement, although a $31.7 \%$ of respondents did not see a clear improvement during DE (answers $\leq 3$ out of 6). The remaining 68.3\% was asked to rank the first three reasons to their answer. Considering these respondents' first choice (see Table 5), we can see the reference to use multiple resources to meet students' learning needs for personalization (33.3\%); to adopt diversified teaching resources (25.9\%); and to use/reuse ready-made materials $(11.1 \%)$, along with the possibility to activate collaborative practices among students $(11.1 \%)$.

Table 5. Distance education perception during the pandemic: improving teaching.

\begin{tabular}{lc}
\hline Prevailing reasons to perceived improvement in teaching, due to distance education ${ }^{\text {a }}$ & Valid percentage \\
\hline It allows me to employ more resources to meet students' learning needs for personalization. & 33.3 \\
It allows me to use diversified teaching resources. & 25.9 \\
It allows me to use/reuse ready-made materials. & 11.1 \\
It allows me to activate collaborative practices among students. & 11.1 \\
It allows me to activate constant evaluative feedback practices. & 8.6 \\
It reduces the time I use for teaching compared to face-to-face modality. & 4.9 \\
It allows me to follow more effectively students with specific learning needs. & 4.9
\end{tabular}

${ }^{a}$ Rank the first three most relevant reasons. Here displayed the percentages for options ranked first.

Furthermore, a specific item inquired about assessment, asking if DE has changed their routines for evaluation (6-point Likert scale). Participants responded with a fair agreement $($ mean $=4.1$, std. $=1.1)$, with a $20.8 \%$ not really seeing a clear modification in evaluating practices during DE (answers $\leq 3$ out of 6 ).

Table 6. Perceived changes in evaluation during DE.

\begin{tabular}{ll}
\hline How distance education changes my evaluating practices ${ }^{\text {a }}$ & Valid percentage $^{\text {I use different evaluation modalities (e.g. projects, reports, tests and }}$ \\
presentations) & 34.9 \\
It is easier to offer more immediate evaluation feedback to students. & 20.9 \\
The overall course grade is made up of scores acquired on several in- & 11.6 \\
progress tests, along with the score of a final examination. & 9.8 \\
It is easier to mark online assignments. & 9.3 \\
I understand more about learning processes with in-progress tests & 7.0 \\
I offer students the opportunity to take an active part in the evaluation & \\
processes. &
\end{tabular}

\footnotetext{
${ }^{6}$ Item 'I find distance education to be an easy way for me to carry out my teaching activity' (6-point Likert scale).
} 
The positive in the tragic. Covid Pandemic as an impetus for change in teaching and assessment in HE

O. Trevisan, M. De Rossi, V. Grion

I cannot track students' assessment processes online.

4.6

I can reduce the number of assessment tasks.

4.6

${ }^{a}$ Rank the first three most relevant reasons. Here displayed the percentages for options ranked first.

Among the more positive respondents (79.2\% overall), 34.9\% ranked using different evaluation modalities as first reason of changed teaching modalities (see Table 6), followed by $20.9 \%$ indicating that DE allows for easier and immediate feedback to the students. Moreover, an $11.6 \%$ of the participants indicated as most relevant change the possibility to realize several in-progress tests, along with final examination. On the other hand, $4.6 \%$ indicated that DE makes it hard for them to track students' learning, and the same percentage also indicated the most relevant change in being able to reduce the number of assessments.

Furthermore, $7 \%$ of the participants ranked as first reason of change the possibility to make students take an active part in the evaluation process, and the same percentage indicated as DE makes it easier to mark online assignments.

\subsection{Teaching practices beyond the pandemic}

In the survey, participants were asked about the possibility of implementing some of the strategies, tools and/or approaches experimented during DE, in their future practices. While a $7.5 \%$ was at best skeptical about it (answers $\leq 3$ out of 6-point Likert scale), a resounding 91.7\% indicated being mildly to very open to it (answers $\geq 4$ out of 6)7. This accounts for the encouraging mean of the broader Resolution factor at 4.7 on a 6-point Likert scale $($ std. $=.87-$ see Trevisan et al., 2020), inquiring whether participants would find DE useful in any way to their future teaching practices.

Investigating deeper into what the more open TPCE would likely carry along in the future (91.7\% overall), we can see how $25.4 \%$ of them will structure teaching as a blended activity (see Table 7 ), followed by $23.6 \%$ open to use technological tools to improve face-to-face interaction and $22.7 \%$ possibly seeking to offer some online lessons/activities. Moreover, $12.7 \%$ of the participants indicated interest in using DE resources to encourage collaborative activities among the students.

Table 7. Distance education elements to be included in usual teaching post-pandemic.

\begin{tabular}{lc}
\hline $\begin{array}{l}\text { How I think I will integrate some technological resources of distance education into my face-to-face } \\
\text { teaching a }\end{array}$ & Valid percentage \\
\hline I will structure teaching as a blended activity. & 25.4 \\
I will use technological tools to improve the face-to-face interaction (e.g. Padlet, Quiziz...). & 23.6 \\
I will offer some online lessons/activities. & 22.7 \\
I will use the resources of distance education to encourage collaborative activities among students. & 12.7 \\
I will use distance education resources to improve student productivity. & 8.2 \\
I will use the resources of distance education to promote accessibility for students with various types of & 7.3 \\
difficulties. &
\end{tabular}

${ }^{\text {a }}$ Rank the first three most relevant reasons. Here displayed the percentages for options ranked first.

\section{Discussion and conclusions}

While other recent researches on the impact of Emergency Education engage faculty working in the multiplicity of higher education courses, both internationally (Butler-Henderson et al., 2020) and nationally (De Rossi et al., 2020), the present study purposely includes higher education faculty commitment to teaching in courses aimed at professionalizing in the educational area. As mentioned above, we wanted to investigate how they responded to the pressure of using DE, considering that the educational objectives of professionalizing courses in the educational area tend to involve methodological approaches more focused on the development of skills and competencies, than just knowledge (Perry et al., 2019).

When analysing the pre-COVID teaching situation, the preference for using the exclusive frontal lecture format appears in a small percentage (12.5\%), whereas its combination with group activities seems to be more widespread (64.2\%), confirming what is reported by the review of initial teacher education by Perry et al. (2019).

\footnotetext{
${ }^{7}$ Six-point Likert scale item 'I think that, once the COVID19 emergency is over, I will integrate some technological resources of distance education into my face-to-face teaching': 1= strongly disagree to $6=$ strongly agree.
} 
Interestingly, up to $68.4 \%$ of the participants indicated among their two most commonly used didactic formats the implementation of online activities. However, deeper analysis shows that most of them intended online activities as a means to share materials with their students $(57.3 \%)$, and only a small percentage to make students active producers (15.6\%). Concerning assessment processes, only $13.3 \%$ of the teachers recognized using technology at some level; however without specifying whether this technology support takes place in person or at a distance.

From the results of the study, technologies integration prior to the pandemic, whilst present, did not fully meet the criteria of quality technology use to make teaching effectively student-centred.

Comparing the pre-COVID data with the DE experience during the pandemic, some considerations can be made.

During the pandemic, TPCE indicated advantages in undertaking distance learning (DE) for practical and personal reasons such as the satisfaction of work-life balance needs $(28.2 \%)$ and communication with students $(20.5 \%)$. A good percentage of TPCE (over 30\%) used digital resources available online as teaching resources (15.4\%), even with an effort to adapt them to the specific characteristics of their course $(16.7 \%)$.

An encouraging finding comes from an analysis of TPCE's perceptions of the impact of DE on the quality of their teaching. Among the $68 \%$ of those who noted an improvement in teaching quality during DE, $33.3 \%$ attributed it to the possibility of adopting teaching strategies aimed at personalizing learning and $25.9 \%$ to the potential to make diverse use of resources through the integration of ICT.

Aligning with Sambell and Brown's (2019) work, findings highlight a positive perception of DE-induced change concerning assessment strategies and tools. Prior to the pandemic, a maximum of $13.3 \%$ of the TPCEs used technology in some way to carry out assessment, while thanks to the forced experience derived from the DE, $80 \%$ declared to have changed their assessment practices: formative assessment was regarded more highly than before; and a process-oriented evaluation was more considered than the previous product-oriented assessment. The perception of change concerned the possibility of using diversified methods of assessment (34.9\%), and of giving and receiving immediate feedback to/from students $(20.9 \%)$ as well as the ease of proposing ongoing tests along with a final exam (11.6\%). Although smaller as a percentage $(7 \%)$, the attention to student involvement in assessment practices should also be noted.

In the part of the survey relating to post-pandemic educational hypotheses, a high percentage of respondents declared an interest in continuing to integrate typical DE formats into their routines $(91.7 \%)$. These TPCE cited several motivations, suggesting a matured awareness of the potential of integrating technologies in the educational setting.

Teachers showed a great interest in being able to implement blended learning formats (25.4\%), which could allow for an important integration of ICT by reshaping learning spaces and times, and they also expressed the intention to continue to offer some online activities in their teaching (22.7\%). TPCEs also showed interest in implementing the use of technological resources to enhance interaction in face-to-face teaching contexts $(23.6 \%)$.

The results highlight TPCE gained awareness regarding both the use of DE resources to improve student productivity $(8.2 \%)$, and to improve the accessibility of students with various types of difficulties (7.3\%), as also reported in Crawford's (2020) study, and to encourage collaborative processes (12.7\%) as a mode of positive interaction (similarly to Robert, 2009).

This exploratory study, although limited in sample size, allowed us to investigate a specific population (TPCE) not truly targeted by other research conducted in the pandemic context (Butler-Henderson et al., 2020). DE conceptualization, in TPCE's case, is more complex because the courses' aims are peculiar to skill development: this implies the adoption of an active approach making methodological and evaluative choices with technologies particularly challenging (European Commission, 2013). However, although in a situation of forced and sudden change, the data emerging in this study shows teachers' tendency to grasp and enhance the potential of DE, precisely in those aspects that characterize initial training for the educational professions (Perry et al, 2019). It would be interesting to continue the study in a longitudinal perspective, expanding the sample, with the aim of investigating what is the actual realization of the transformative intentions stated by teachers in relation to the integrated use of ICT, at the time of the return to normal.

\section{References}

Bernard, R. M., Abrami, P.C., Borokhovski, E., Wade, C. A., Tamim, R. M., Surkes, M. A. and Bethel, E. C. (2009). A Meta-Analysis of Three Types of Interaction Treatments in Distance Education. Review of Educational Research, 79(3), 1243-1289

Brown, S. (2015). Learning, teaching and assessment in higher education: Global perspectives. London: PalgraveMacmillan.

Butler-Henderson, K, Crawford, J, Rudolph, J, Lalani, K \& Sabu, K.M. (2020). COVID-19 in Higher Education Literature Database (CHELD V1): An open access systematic literature review database with coding rules. Journal of Applied Learning \& Teaching, 3(2), pp. 1-6.

Corsi, M., Giannandrea, L., Rossi, P. G., \& Pons, J. D. P. (2019). Innovating didactics at university. Education Sciences \& Society-Open Access Journal, 9(2), 1-7. http://dx.doi.org/10.3280/ess2-20180a7331 


\section{The positive in the tragic. Covid Pandemic as an impetus for change in teaching and assessment in HE}

\section{O. Trevisan, M. De Rossi, V. Grion}

Crawford, J., Butler-Henderson, K., Rudolph, J., Malkawi, B., Glowatz, M., Burton, R., Magni, P.A., \& Lam, S. (2020). COVID-19: 20 countries' higher education intra-period digital pedagogy responses. Journal of Applied Learning \& Teaching, 3(1), 9-28. https://doi.org/10.37074/jalt.2020.3.1.7

De Rossi, M. (2019). Teaching Methodologies for Educational Design. N.Y.-Milano: McGraw-Hill.

De Rossi, M., Ferranti, C. (2017). Integrare le ICT nella didattica universitaria. Padova: Padua University Press.

De Rossi, M., Grion, V., \& Trevisan, O. (2020). La "Normalizzazione” delle ICT in Emergenza Formativa: Come

European Commission (2013). Supporting teacher competence development for better learning outcomes. Brussels: EC. https://ec.europa.eu/assets/eac/education/policy/school/doc/teachercomp_en.pdf

European Commission (2020). Digital Education. Action Plan 2021-2027. Resetting education and training for the digital age. https://eur-lex.europa.eu/legal-content/EN/TXT/?qid=1602778451601\&uri=CELEX:52020DC0624

Fedeli, M., Mapelli, D., Mariconda, C. (2020) (Eds.). Teaching4Learning. L'innovazione didattica all'Università di Padova. Teorie, ricerche e pratiche. Padova: Padova University Press.

Gaebel, M., Kupriyanova, V., Morais, R. \& Colucci, E. (2014). E-Learning in European Higher Education Institutions. Brussels: European University. Association (EUA).

Gaebel, M., Zhang, T. (Eds.) (2018). Trends 2018: Learning and teaching in the European Higher Education Area. Brussels: EUA. Retrieved from https://eua.eu/resources/publications/757:trends-2018-learning-and-teaching-inthe-european-higher-education-area.html

Garrison, D.R., \& Vaughan, N.D. (2008). Blended learning in higher education: Framework, principles, and guidelines. San Francisco: John Wiley \& Sons.

Grion V., Serbati A. (2019). Valutazione sostenibile e feedback nei contesti universitari. Prospettive emergenti, ricerche e pratiche, Lecce: PensaMultimedia, ISSN: 2283-5806

High Level Group on the Modernisation of Higher Education (2013). Improving the quality of teaching and learning in Europe's higher education institutions. Luxemburg: European Union.

Hodges, C., Moore, S., Lockee, B., Trust, T., \& Bond, A. (2020). The Difference Between Emergency Remote Teaching and Online Learning. Educasereview. Retrieved from https://er.educause.edu/articles/2020/3/thedifferencebetween-emergency-remote-teaching-and-online-learning.

Joughin, G. Dawson, P. \& Boud, D. (2017) Improving assessment tasks through addressing our unconscious limits to change, Assessment \& Evaluation in Higher Education, 42(8), 1221-1232. Doi: 10.1080/02602938.2016.1257689

Khaddage, F., Fayad, R. \& Moussallem, I. (2020). Online Learning and the Role of Technologies During COVID19 Pandemic "Higher Education Lebanon Case". In Proceedings of EdMedia + Innovate Learning (pp. 623-630). Online, The Netherlands: Association for the Advancement of Computing in Education (AACE). https://www.learntechlib.org/primary/p/217361/.

Lowenthal, P., Borup, J., West, R. E., \& Archambault, L. (2020). Thinking Beyond Zoom: Using Asynchronous Video to Maintain Connection and Engagement During the COVID-19 Pandemic. Journal of Technology and Teacher Education, 28(2), 383-391. Milman, N. (2020, March 30).

Major, C.H. (2015). Teaching online: A guide to theory, research, and practice. Baltimore, Maryland: Johns Hopkins University Press.

Moore, J.L., Dickson-Deane, C., \& Galyen, K. (2011). E-Learning, online learning, and distance learning environments: Are they the same?. The Internet and Higher Education , 14(2), 129-135.

Moore, M.G., \& Diehl, W.C. (Eds.) (2018). Handbook of Distance Education (4nd ed.). N.Y.: Routledge.

Perry E., Booth J., Owen D., Bower K., (2019) The Curriculum for Initial Teacher Education: Literature Review,

Risponde l'Università?. Online presentation at SIREM - Società Italiana di Ricerca sull'Educazione Mediale, 8/07/2020

Safi, F., Wenzel, T. \& Spalding, L.T. (2020). Remote Learning Community: Supporting Teacher Educators During Unprecedented Times. Journal of Technology and Teacher Education, 28(2), 211-222.

Sambell, K. \& Brown, S. (2019): The changing landscape of assessment: some possible replacements for unseen, timeconstrained, face-to-face invigilated exams. In K. Sambell \& S. Brown, Covid-19 Assessment Collection, Published on 1st June, 2020. Retrieved from https://sally-brown.net/kay-sambell-and-sally-brown-covid-19assessment-collection/

Trevisan, O., Knezek, G., De Rossi, M., Grion, V., \& Christensen, R. (2020). Technology and Distance Teaching during the COVID-19 Pandemic: Deriving Constructs from an International Higher Education Survey. In E. Langran (Ed.), Proceedings of SITE Interactive 2020 Online Conference (pp. 222-228). Online: Association for the Advancement of Computing in Education (AACE). Retrieved November 16, 2020 from https://www.learntechlib.org/primary/p/218148/.

UNESCO. (2020). COVID-19 Educational disruption and response. Retrieved from https://en.unesco.org/themes/educationemergencies/coronavirus-school-closures. 